\title{
Measures of the Consumer Food Store Environment: A Systematic Review of the Evidence 2000-2011
}

\author{
Alison Gustafson $\cdot$ Scott Hankins $\cdot$ Stephanie Jilcott
}

Published online: 10 December 2011

(c) The Author(s) 2011. This article is published with open access at Springerlink.com

\begin{abstract}
Description of the consumer food environment has proliferated in publication. However, there has been a lack of systematic reviews focusing on how the consumer food environment is associated with the following: (1) neighborhood characteristics; (2) food prices; (3) dietary patterns; and (4) weight status. We conducted a systematic review of primary, quantitative, observational studies, published in English that conducted an audit of the consumer food environment. The literature search included electronic, hand searches, and peer-reviewed from 2000 to 2011. Fifty six papers met the inclusion criteria. Six studies reported stores in low income neighborhoods or high minority neighborhoods had less availability of healthy food. While, four studies found there was no difference in availability between neighborhoods. The results were also inconsistent for differences in food prices, dietary patterns, and weight status. This systematic review uncovered several key findings. (1) Systematic measurement of determining availability of food within stores and store types is needed; (2) Context is relevant for understanding the complexities of the consumer food environment; (3) Interventions and longitudinal studies addressing purchasing habits, diet, and obesity outcomes are needed; and (4)
\end{abstract}

\footnotetext{
A. Gustafson $(\bowtie)$

Department of Nutrition and Food Science,

University of Kentucky, 206G Funkhouser,

Lexington, KY 40506, USA

e-mail: alison.gustafson@uky.edu

S. Hankins

College of Public Health, University of Kentucky,

Lexington, KY 40506, USA

S. Jilcott

Department of Public Health, Brody School of Medicine,

East Carolina University, 1709 West Sixth St.,

Greenville, NC 27834, USA
}

Influences of price and marketing that may be linked with why people purchase certain items.

Keywords Food environment · Community

\section{Introduction}

As obesity continues to plague the US, presenting major public health and economic challenges [8], researchers and policy makers examine the potential for preventing obesity through changes to the food environment [79]. Both macroand micro-level factors in the food environment may influence dietary patterns and obesity. For the purposes of this paper, we define the macro-level food environment as access to food venues such as supermarkets and fast-food restaurants $[38,79]$. As such, the macro-level food environment may be one causal factor in the pathway to an unhealthy diet and subsequent obesity [35]. At the micro level, the consumer food environment, or the food options within a store where individuals purchase food, may also be a causal factor in the development and progression of unhealthy diet and subsequent obesity [70].

Despite the conceptual frameworks as described by Story et al. [38] and Glanz et al. [79] featuring food environment change, findings for many environmental features are inconsistent, whether at the micro or macro level, and between geographic locations $[5,15,31,36,58$, 66]. Studies at the macro-level, assessing proximity and coverage of types of food outlets and the rates of obesity or dietary intake have found mixed results. In regards to coverage of types of food outlets, several studies report that neighborhoods with high minority composition or lowincome residents have fewer supermarkets and more convenience stores and fast-food restaurants [11, 64, 71]. 
Although it may be well understood that certain lowincome or minority neighborhoods have less supermarkets and grocery stores, recent research has begun to uncover that proximity to certain establishments is not necessarily associated with diet and weight outcomes [10, 12]. Although cross-sectional studies in rural settings report proximity to fast-food restaurants with higher body mass index (BMI) or greater odds of obesity [50, 74, 78], a longitudinal study in urban settings reported that those residents living closer to fast-food restaurants do not report higher BMI or greater consumption [10]. Additionally, a longitudinal study conducted in urban settings assessed the association between proximity to supermarkets and intake of fruits and vegetables, and found a null association [12].

Most reviews have focused on the macro-level food environment [30, 62] with specific attention given to understanding the evidence as it relates to the micro-level, or consumer food environment (food availability within stores) [7], and the relationships between neighborhood characteristics, food prices, dietary patterns, and weight status. However, of the studies focusing on the micro-level consumer food environment, the results are inconsistent. Overall, findings suggest that those who shop at locations with generally healthier food options, do not report lower BMI or higher intake of fruits and vegetables [41, 45, 37, 81]. However, there are studies which report that those living in low-income neighborhoods report a lower healthy eating index, indicating lower diet quality [32, 33]. When studies use a food store audit tool to measure fruit and vegetable prices within stores and the association with intake or BMI, the results suggest that lower prices of fruits and vegetables are associated with lower increases in BMI [80]. Additionally, a cross-sectional study found an inverse relationship between neighborhood availability of fruits and vegetables and BMI [47], such that the higher fruit and vegetables availability, the lower the self- reported BMI.

Given that recent research has focused on food availability within stores, a review of the evidence is warranted to gain better insight into the complexities of using food store audit tools to measure food availability within stores. Indeed, the recent attention given to understanding the store contents where people live and shop can be seen with a surge in publication between 2000 and 2011. In the years 2000-2003 there were 4 papers published, while in 2008-2011 there were 35 papers. The sharp increase in the number of publications regarding the micro-level store consumer food environment suggests that this is a critical research area that needs further focus. Based on the lack of systematic reviews focusing on the consumer food environment, our aim was to present an assessment of recent literature focusing on the association between the consumer food environment and the following: neighborhood characteristics; (2) food prices; (3) dietary patterns; and; (4) weight status.

\section{Methods}

The purpose of this review was to evaluate the literature for evidence of the association between the consumer food store environment and neighborhood characteristics, food prices, dietary patterns, and weight status. Our search in PubMed (National Library of Medicine, Bethesda, Maryland) included the medical subject headings (MeSH) "obesity" or "overweight" and "environment," "built environment", "retail," "food store," "food environment", "food retail", "diet", "fruit and vegetable", "fruit" or "vegetable", "snack food", and "food audit". The search was restricted to studies published in English examining the in-store food contents. The initial search returned 617 papers. We excluded studies which did not conduct a food store audit, or checklist, or market basket, or inventory. We also excluded papers that presented findings on developing the audit, checklist, or inventory. We excluded papers published before 2000 since several reviews have published this data [7, 62]. This left us with 47 eligible papers.

These manuscripts were compared with two literature reviews [7, 62] and one federal website listing food store environment resources and associated manuscripts (National Cancer Institute Food Environment Instruments https:// riskfactor.cancer.gov/mfe/instruments). There were an additional 10 manuscripts identified when comparing the list of 46 with the other review papers and federal web site resource. The list was then circulated to a content expert to verify the list of manuscripts. These steps resulted in a total of 56 papers (Table 1) which were then evaluated with a primary goal to compare and contrast study outcomes. We grouped papers by common food store instruments, geographic region (rural vs. urban), and outcomes (neighborhood characteristics, food prices, dietary patterns, and weight status). Papers were grouped based on methods and location described in each manuscript. Reviewers verified rural and urban classification based on the USDA rural codes [28]. For manuscripts conducted outside of the United States if the authors indicated the study was conducted in a rural environment the study was classified as rural. The outcomes were classified based on manuscript aims and hypothesis statements as well as result and tables sections.

\section{Results}

Of the 56 papers considered acceptable for the review, 39 were conducted in urban settings, while 13 were conducted in rural settings, and 4 were conducted in both urban and rural settings (Table 2). A majority of the papers were conducted in the 


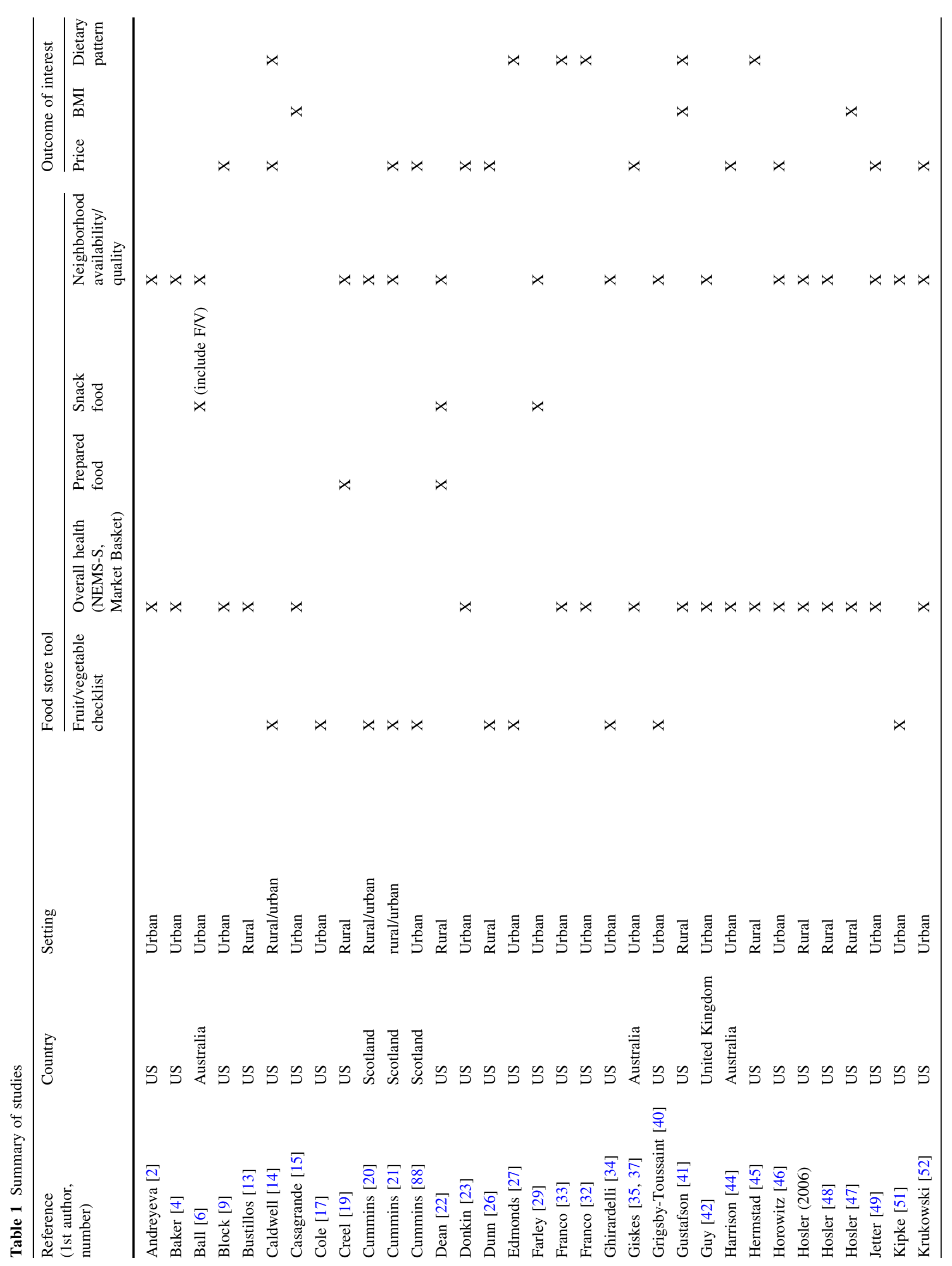




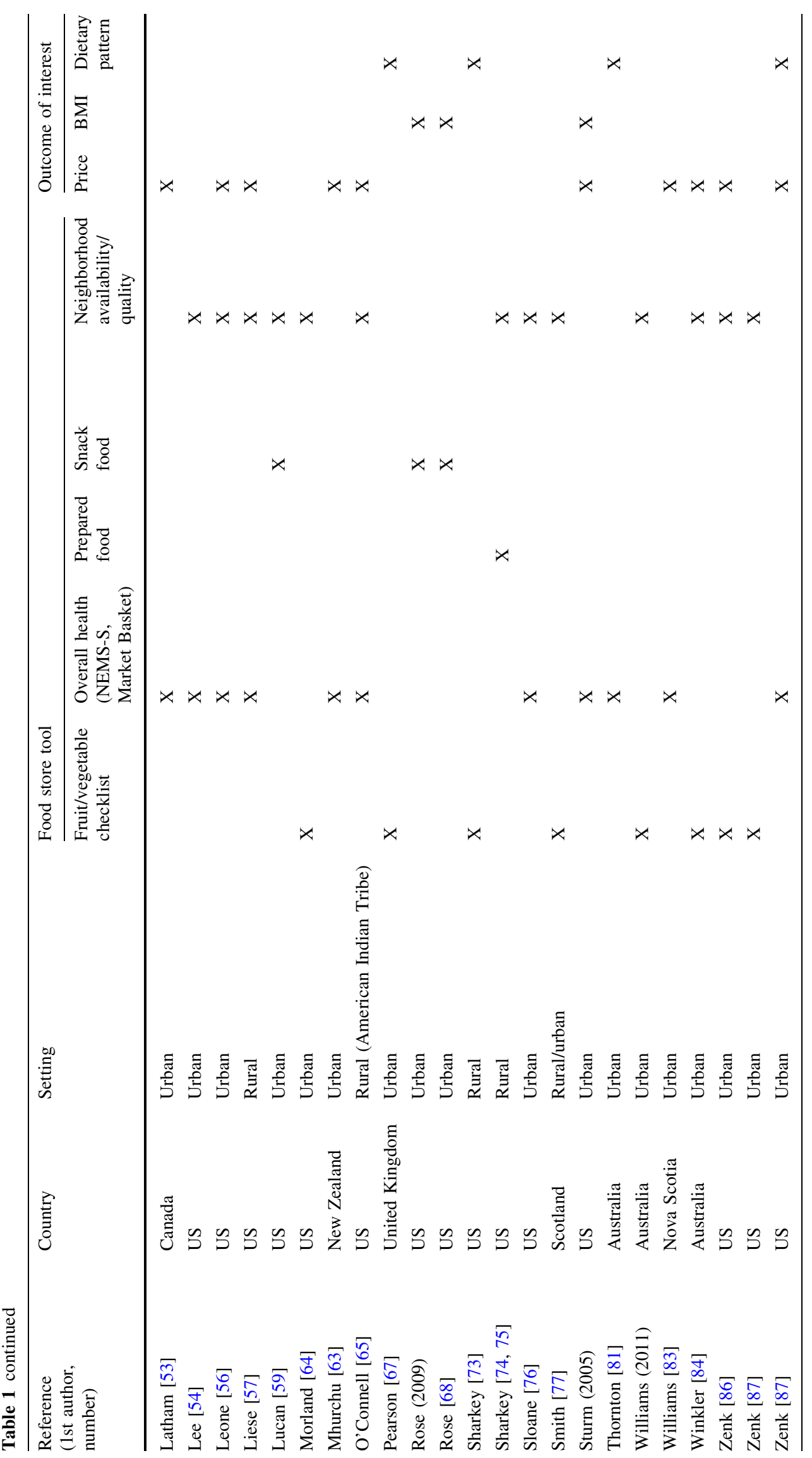


Table 2 Study characteristics summarized 2000-2011

\begin{tabular}{|c|c|c|}
\hline$(\mathrm{n}=56)$ & & $\begin{array}{l}\mathrm{N} \text { (Percentage } \\
\text { of total) }\end{array}$ \\
\hline \multirow[t]{3}{*}{ Study setting } & Rural & $13(23)$ \\
\hline & Urban & $39(70)$ \\
\hline & Both rural/urban & $4(7)$ \\
\hline \multirow[t]{7}{*}{ Country } & United States & $41(73)$ \\
\hline & Australia & $6(11)$ \\
\hline & Canada & $1(2)$ \\
\hline & United Kingdom & $2(4)$ \\
\hline & New Zealand & $1(2)$ \\
\hline & Scotland & $4(7)$ \\
\hline & Nova Scotia & $1(2)$ \\
\hline \multirow[t]{6}{*}{ Food tool used } & Overall availability & $30(52)$ \\
\hline & $\begin{array}{l}\text { Fruit and vegetable } \\
\text { availability only }\end{array}$ & $18(32)$ \\
\hline & Prepared food & $2(4)$ \\
\hline & Snack food & $4(7)$ \\
\hline & $\begin{array}{l}\text { Snack food including } \\
\text { fruit/vegetable }\end{array}$ & $1(2)$ \\
\hline & Prepared and snack food & $1(2)$ \\
\hline \multirow[t]{4}{*}{ Outcome Measured $^{\mathrm{a}}$} & $\begin{array}{l}\text { Neighborhood } \\
\text { availability/quality }\end{array}$ & $30(54)$ \\
\hline & Price & $21(38)$ \\
\hline & Body mass index (BMI) & $6(11)$ \\
\hline & Dietary pattern & $6(11)$ \\
\hline \multirow[t]{3}{*}{ Year published } & $2000-2003$ & $3(5)$ \\
\hline & 2004-2007 & $18(32)$ \\
\hline & 2008-2011 & $35(61)$ \\
\hline
\end{tabular}

a There are double counts since some studies had multiple outcomes

United States $(\mathrm{n}=41)$ with few conducted outside the United States; United Kingdom, including Scotland, $(\mathrm{n}=6)$, Australia $(\mathrm{n}=6)$, Nova Scotia $(\mathrm{n}=1)$, Canada $(\mathrm{n}=1)$, and New Zealand $(n=1)$. The food store audit tool was typically either an overall assessment of several types of food in the store, such as the Nutrition Environment Measurement Survey-Stores (NEMS-S) [39] $(\mathrm{n}=30)$, or a checklist for availability of fruits and vegetables $(n=19)$, with eight studies using a checklist for availability of snack food or prepared food. A majority of the studies looked at neighborhood availability or quality within stores $(\mathrm{n}=30)$ or comparison of prices between healthy and less healthy traditional food items $(n=21)$. Twelve studies examined the association between dietary patterns and weight status relative to in-store food contents.

\section{Overall Food Availability in Stores}

Several researchers used a food store audit tool to assess the store contents. A large percentage of the studies used a tool to look at overall food availability using a market basket of food items which included fruits and vegetables but did not single out produce $(\mathrm{n}=30$ or $52 \%)$. Of the studies assessing overall availability, 23 were conducted in urban settings, and 7 were conducted in rural settings.

\section{Neighborhood Characteristics}

Studies $(\mathrm{n}=30)$ using a market basket tool or an audit (Table 3) to examine the overall healthfulness of food available in the store and the association with neighborhood characteristics, had mixed results. All of these studies used a tool that assessed availability of a range of food items (19-622) based on consumption patterns, health of the food item, ethnic considerations, and geographic location. Of the six studies finding that stores in low income neighborhoods or high minority neighborhoods had less availability of healthy food, all were conducted in the United States [2, 4, 32, 33, 46, 56, 76]. Conversely, there were four studies reporting no association between store availability of healthy food items and neighborhood deprivation $[45,52,84,87]$ or demographic characteristics [52]. Those four studies were conducted in the United States with 3 being in urban settings [52, 84, 87] and the other being in a rural setting [45]. When studies addressed quality of the food items the results shift slightly: two studies reported that the quality of the food items was lower in stores located in low-income neighborhoods $[54,76]$ or that non-traditional food stores carried a variety of quality items [13].

\section{Food Prices}

Of the studies assessing food prices $(\mathrm{n}=16)$, six studies conducted a price comparison between store types (supermarket vs. convenience stores), while four studies conducted a price comparison between neighborhoods (i.e. low socioeconomic status compared to high socioeconomic status), and six studies conducted a price comparison between a healthy basket of food compared to a regular version of the food basket.

Of the studies conducting a price comparison between store types, six studies found that larger grocery stores had cheaper prices for healthy food items compared to smaller grocery stores $[9,42,44,52,53,65]$ and three studies found that convenience stores and gas stations had higher prices compared to grocery and supermarkets [23, 56, 57] for healthy food items.

Two of the studies measuring price differences between neighborhoods found price differences within store types between low and high income neighborhoods [46, 54] conducted in the United States, such that stores in lowincome neighborhoods had higher prices relative to stores 


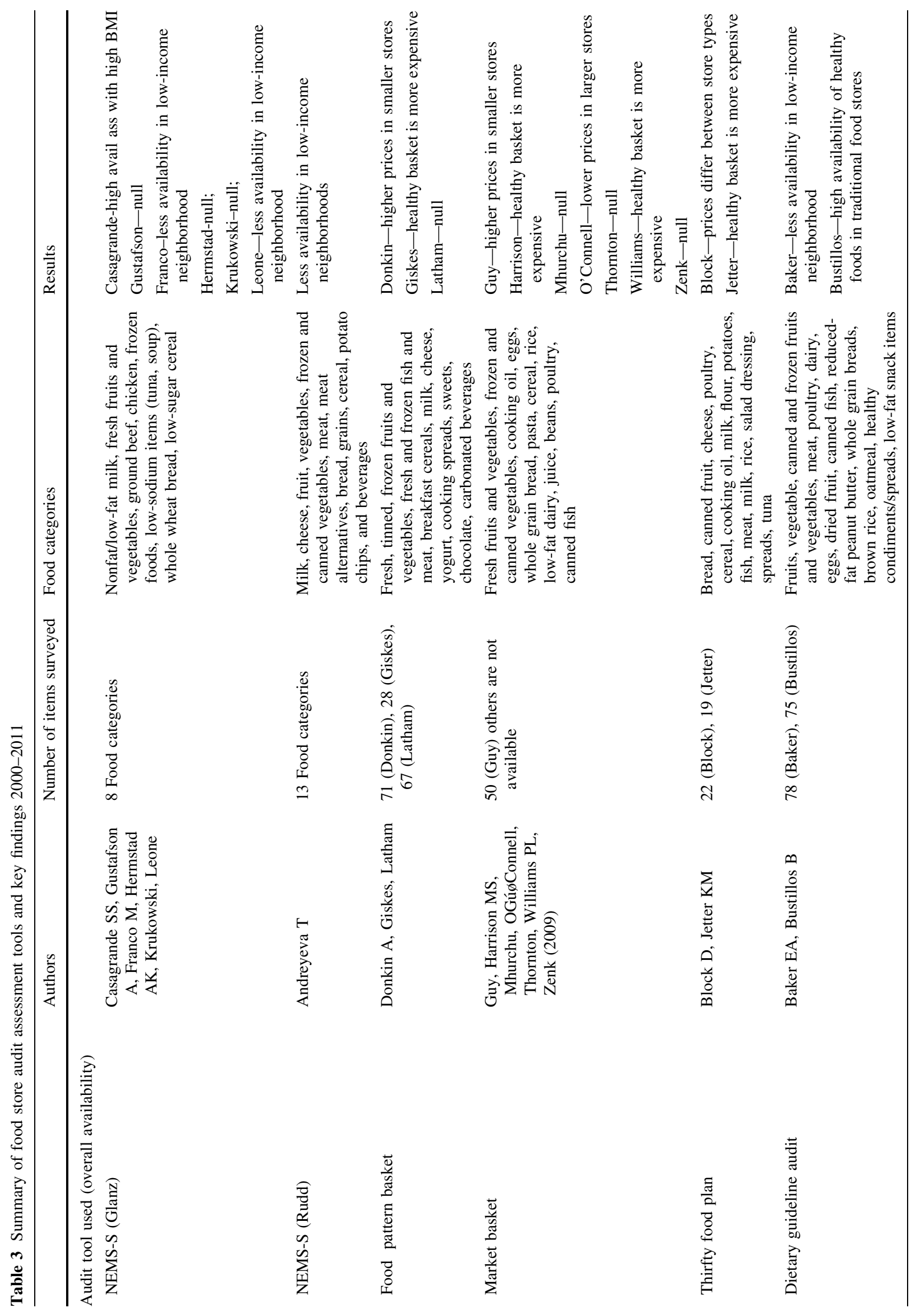




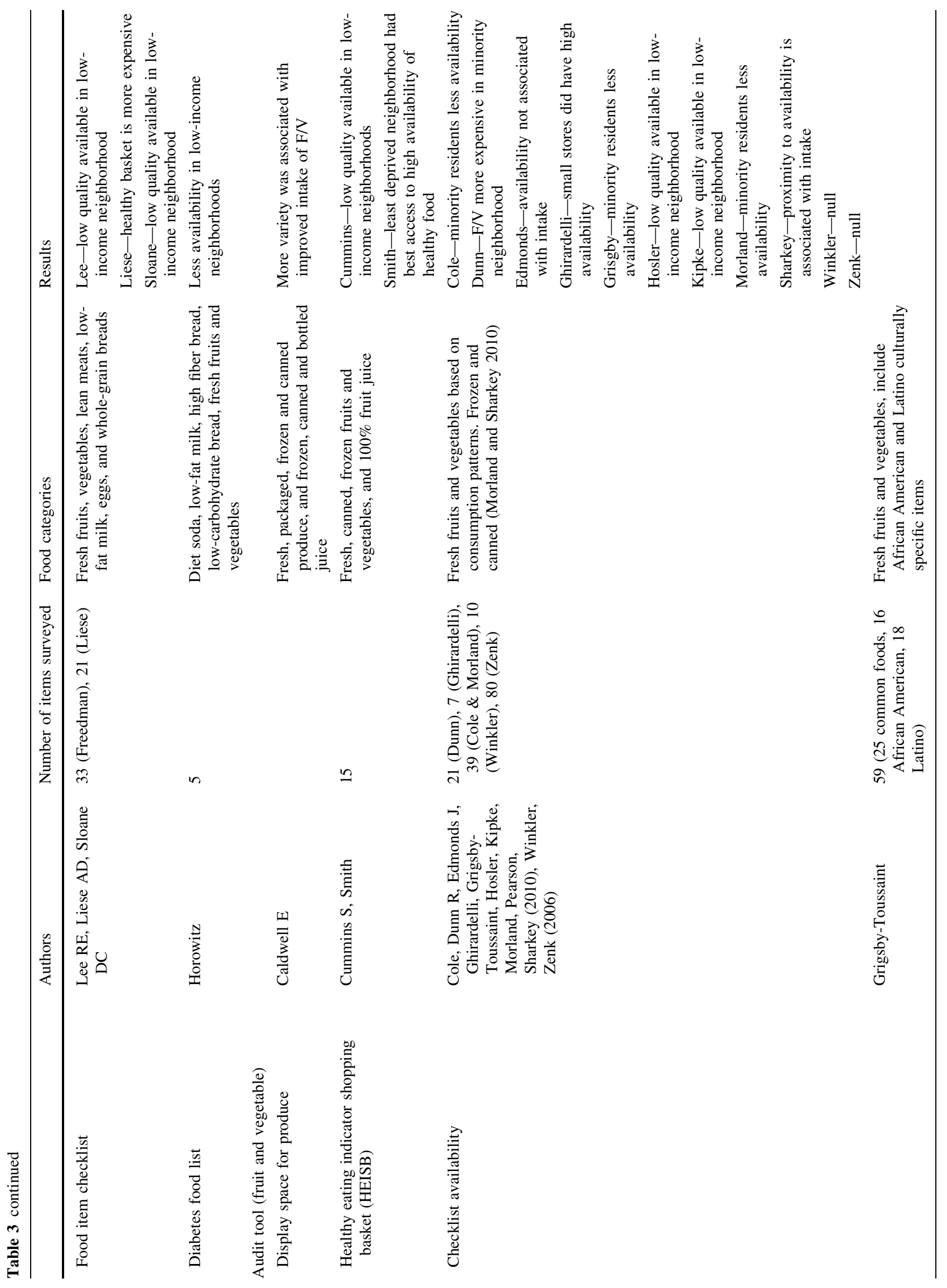




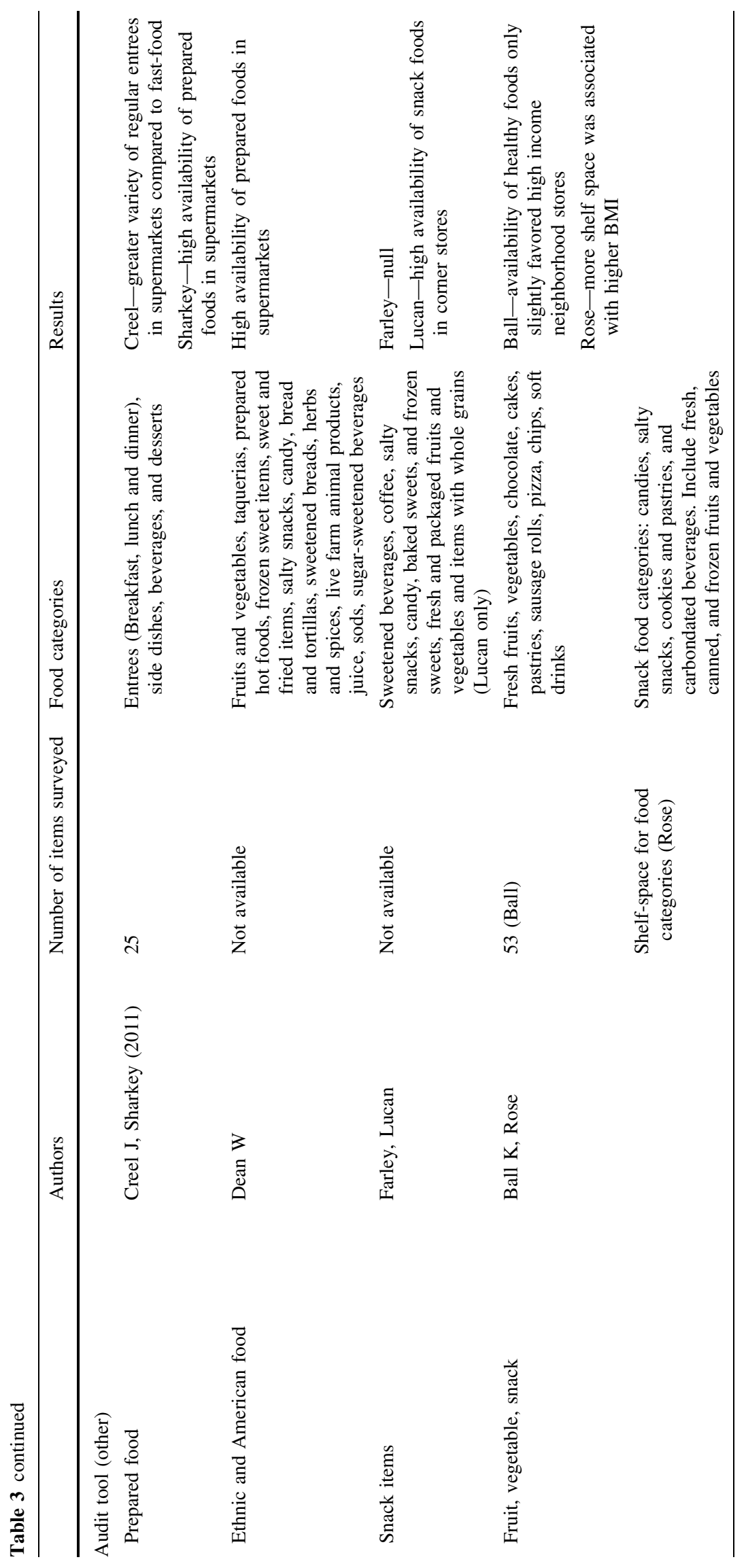


in high income neighborhoods. Yet, two other studies found no significant price differences between supermarkets located in high versus low income neighborhoods $[53,56]$.

Regarding studies conducting a market basket comparison four US-based, urban studies found that the healthier version of the basket was more expensive compared to the regular or government-supported version [49, 57, 83, 37], yet the New Zealand based study found no price differences between the two types of baskets [63]. One study addressed the association between price and purchasing habits and reported no effect of price on purchasing habits, whether the price was measured objectively or through perception of price [35].

\section{Dietary Patterns and Weight Status}

Results of several studies addressing overall in-store food availability with dietary patterns and BMI suggest an association with availability and behavioral and health outcomes in the United States in urban settings. Contrary to conventional thought, high availability of healthy food was associated with high BMI [15], yet in a similar study setting, low availability of healthy foods was associated with a lower healthy eating index score [32]. Two cross-sectional studies conducted in rural settings found no association between store availability and diet or BMI, both using the NEMS-S instrument [41, 45]. Likewise, studies conducted in Australia and the United Kingdom found that overall store availability of healthy foods was not associated with dietary outcomes, or BMI $[35,81]$.

\section{Fruit and Vegetable Availability}

A large percentage of the studies examined availability of fruits and vegetables within stores $(n=18$ or $32 \%)$. The number of fruit and vegetable items collected varied between 7 and 80 . Of the studies assessing fruit and vegetable availability 13 were conducted in urban settings, 4 were conducted in both rural/urban settings, and 2 were conducted in only rural setting.

\section{Neighborhood Characteristics}

The studies examining the association between neighborhood characteristics and fruit and vegetable availability had similar mixed results as those studies assessing overall availability of healthy foods and neighborhood characteristics. Contrasting results were found between studies measuring availability of fruits and vegetables within minority neighborhoods: two studies found that neighborhoods with primarily Black resident had a lower proportion of stores that carried fresh or frozen fruits and vegetables $[17,40,64]$ and one study found the fruits and vegetables were more expensive [26]. Additionally, other studies conducted in urban and minority neighborhoods found a low proportion of quality fruits and vegetables available $[20,21,48,51]$. However, several studies conducted in urban settings in the United States and in the United Kingdom found no difference in availability based on neighborhood characteristics $[67,84,86]$. One study found that those who lived in the most deprived neighborhood actually had the best access to stores with high availability of healthy foods [77]. Lastly, one study found that many small markets in low-income neighborhoods did carry a moderate or better variety of fresh fruits and vegetables [34] when compared to higher income neighborhoods.

\section{Food Prices}

Several studies examined price differences between fruits and vegetables within neighborhoods (minority or lowincome) and within store types (supermarket vs. convenience). The results indicate that overall prices of fruits and vegetables did not differ based on neighborhood characteristics $[21,84,86]$. One study addressed mean cost of meeting the USDA-recommended level of fruit and vegetable consumption. This study reported that relying on a limited variety of fruits and vegetables cost much less than relying on a higher variety of less commonly available fruits and vegetables [26].

\section{Dietary Patterns and Weight Status}

Of the limited studies with an aim of determining the association between availability of fruits and vegetables and dietary patterns and weigh status there are mixed results, largely based on geographic location.

\section{Consumption of Fruits and Vegetable as an Outcome}

One study conducted in an urban US setting found that availability of fruits and vegetables in stores was not associated with consumption [27]. Complementary to this finding were results from a study conducted in urban United Kingdom which found price of fruits and vegetables was not associated with consumption [67]. However, a study conducted among rural seniors reported that proximity to stores with a high availability of fruits and vegetables reported a greater intake of fruit [73]. Additionally, another cross-sectional study found that fruit and vegetable consumption decreased as price increased for fruits and vegetables [14]. Lastly, those living in communities with grocery stores that had more varieties of produce had on average greater increases in fruit and vegetable intake, over a 12-month period, [14] compared to those 
living in communities with grocery stores that had fewer varieties of produce.

\section{BMI as an Outcome}

Studies addressing the association between fruit and vegetable availability and BMI found that lower prices of fruits and vegetables predicted lower gains in BMI [80], while a cross-sectional study found an inverse relationship between availability of fruits and vegetables with BMI [47], such that the more fruits and vegetables that were available the lower the self-reported BMI.

\section{Snack Foods and Prepared Foods}

There were eight separate author studies assessing the availability of energy dense snack food items or snack food items including fruits and vegetables within stores [5, 29, $59,69,70]$, or prepared foods or prepared and snack food [22, 54, 74, 19]. The studies addressing snack food availability were all conducted in urban areas; whereas the studies assessing availability of prepared foods were conducted in both rural $(n=3)$ and urban settings $(n=1)$.

\section{Neighborhood Characteristics}

Of the 8 studies reporting on prepared and snack food, four studies reported high availability of energy dense snacks in corner stores [59], gas stations and pharmacies [29], and supermarkets $[69,70]$ relative to healthy food items. One study found that healthy items slightly favored higher income neighborhood stores relative to lower income neighborhood stores [6]. However, a study conducted in 19 urban cities found no significant difference between household income or percentage minority and availability of energy dense snack items [29]. In regards to availability of prepared food items, such as rotisserie chicken, two studies reported high availability of prepared food items in grocery stores and smaller stores [22, 74] and these stores or pulgas were found in deprived neighborhoods (those neighborhoods with a high proportion of low-income, loweducation, high poverty individuals). Lastly, one study addressed availability of prepared food within store types, finding supermarket/grocery stores provided a greater variety of regular entrees and side dishes than traditional fast food outlets or convenience stores [19].

\section{Food Prices}

The studies focusing on availability of snack foods and prepared foods did not conduct comparison between healthy snack items with energy dense snack items. Nor did these studies conduct a comparison between store types and price of snack foods.

Dietary Patterns and Weight Status

One author over 2 years reported on availability of energy dense snack food and the association with BMI. In both manuscripts the results indicated that more shelf-space for energy dense snack food was associated with a higher BMI $[68,70]$.

\section{Discussion and Recommendations}

This systematic review uncovered several key findings. (1) Systematic measurement of determining availability of food within stores and store types is needed; (2) Context is relevant for understanding the complexities of the consumer food environment within different settings; (3) Interventions and longitudinal studies addressing purchasing habits, diet, and obesity outcomes are needed; and (4) Influences of price, marketing, and other behaviors that may be linked with why people purchase certain items. Based on these key finding the following recommendations are made.

Systematic Measurement of Determining Availability of Food Within Stores and Store Types

The review suggests there is a wide range of food store audit tools assessing overall availability and availability of fruits and vegetables (Table 3). While all audits included fresh fruits and vegetables, some audits included low-fat dairy, cooking oils and spreads, while others included low-fat snack items. Although it is important to address geographic, racial, and ethnic differences, the wide range of items collected make comparisons between studies difficult. Additionally, it is difficult to ascertain from the variety of tools, which are the key food items that need to be included on food store audits to accurately assess the "health" of the store. To further complicate matters, science on diet and health is changing at a rapid pace, and recent recommendations do not encourage low-fat consumption, rather focusing on fat quality [61, 82]. To these ends food store audit tools need to be streamlined to include the most relevant food items to, reflect the health of the store, and remain fluid rather than static to address current scientific recommendations regarding diet and health.

Context is Relevant for Understanding the Complexities of the Consumer Food Environment

There is a vast difference in results between studies conducted in the United States relative to other studies, such 
that those studies in the United States tended to find differences between neighborhoods and prices for availability of healthier food items, whereas studies conducted in other countries generally reported no association. The lack of consistency between studies points to the complex nature of measuring the food store environment within diverse settings and store types. Recent results have pointed to the variety in types of supermarkets and the variety of food offered within these stores [25]. By lumping together "supermarkets" into one category, very important differences within this category are being missed [55]. Key differences between supermarkets in low-income versus high-income neighborhoods, such as lighting, safety, and crime rates, are not traditionally reported. A more comprehensive description of the store, along with the surrounding neighborhood is needed to understand the context in which individuals shop and therefore the association between neighborhood characteristics and the consumer food environment.

Complementary to understanding the neighborhood aesthetics several additional key variables are needed to understand the dynamic between store location, individual access, and prices. Convenience stores by definition are going to offer their goods at a higher price based on economies of scale. By comparing prices of healthy foods between convenience stores and larger grocery store the food at convenience stores will almost always be more expensive and thus this information does little to help inform policy with regard to price effects of healthy food relative to regular food items. The research question that might be more relevant is examining how competition, location of stores, and individual income all work together to drive price and availability of items. These three variables all push and pull with and against each other to determine price of food. Future research needs to consider these variables when aiming to understand the intersection between food price, consumer behavior, and health outcomes.

The review found that a small percentage of the studies were conducted in rural areas $(n=1730 \%)$. The lack of research focusing on rural communities highlights the need for future research to focus not only on urban settings but rural as well. Given, that a large proportion of rural residents live in food deserts, determining the extent to which the consumer environment influences diet and obesity among those most at risk for diet and disease is an essential. Additionally most studies have used in-store measurement techniques that are well suited for supermarkets, corner stores, and small grocery store. However, recent research has highlighted the need to assess non-traditional food venues, such as dollar stores and pharmacies, particularly in rural areas [75]. Research has shown that a large proportion of rural residents shop at non-traditional food outlets [41, 72, 75]. Given the trend in non-traditional food store shopping measurement tools need to be adapted to adequately address these venues in order to accurately measure the consumer food environment.

Lastly, capturing patterns of shopping habits is needed to understand the nature of how individuals live within their various communities, such as work versus home. There were few studies that reported whether individuals chose to shop for food because of proximity to home, work, or other [41]. Of those studies the results reported that a majority chose their food store because of proximity to home. However, what is missing is understanding how availability of certain foods within stores may influence store choice and therefore other food choices once inside. Future studies need to capture daily patterns of food shopping as well as understanding why individuals chose the stores they do.

Interventions and Longitudinal Studies Addressing Purchasing Habits, Diet, and Obesity Outcomes to Better Examine the Intersection

The research to date has made efforts to highlight the complex nature of the individual within their neighborhood and the locations they frequent for food. Yet, additional knowledge is needed to uncover the complex nature of the bidirectional nature of the environment and the individual. There was one longitudinal study which found that lower prices in fruits and vegetables predicted lower gains in BMI [80]. This result is promising but needs to be replicated in order to understand the potential mechanisms by which the environment influences health outcomes. Additionally, this study addressed price, while there remains a large gap in understanding how the environment influences purchasing habits, diet and obesity overtime. Although recent longitudinal studies found that overtime living close to supermarkets or fast-food restaurants did not predict intake $[10,12]$ these studies did not assess the consumer food environment. Where individuals shop and eat, rather than just proximity to certain store types, is most important [60].

Recent cross-sectional results point to that women participating in a weight-loss intervention living in rural communities with limited access to supermarkets actually increased their intake of fruits and vegetables (Gustafson, A J Nutrition and Metabolism 2011). This result indicates that an intervention may help to decrease perceived and real barriers to purchasing fruits and vegetables. Future interventions should address the environment where individuals live, work, and play to see meaningful results. 
Influences of Price, and Marketing may be Linked with Why People Purchase Certain Food Items

\section{Price}

There has been much debate in understanding the influence price has on consumer intake of healthy food items. Several studies have indicated that consumers cite price as a barrier to purchasing healthy foods [3, 16, 85]. Our review found that several studies conducted price comparison between store types and between healthy and regular food baskets. The results were mixed between store types and neighborhood characteristics such that, certain studies found prices differences between store types and neighborhoods when comparing healthy food items, whereas others did not find differences. Given the conflicting results efforts should be aimed at understanding at what price will consumers move from an unhealthy or regular food item to the more affordable healthier choice. Recent studies have found that as gas price increases, body weight decreases, [18] suggesting that consumers spend less on unhealthy food items or food in general, or more likely to be walking. Yet, studies point to the high cost a healthy diet has on lowincome consumers $[1,24,25]$. To better understand how price influences purchasing habits, natural experiments assessing price fluctuations and the influence on consumer purchasing habits are warranted. Moreover, community level interventions aimed at reducing prices may help to elucidate the intersection between the individual and the consumer food environment with regard to price.

\section{Marketing}

There has been attention in recent years on how marketing to children influences food preferences and intake [43]. However, in this systematic review, none of the studies mentioned marketing within stores and the influence that may have on why individuals choose certain food items. Few tools examine placement of products or advertisements for products. For example, although supercenters score high on NEMS-S, supercenters thrive on selling in bulk, and advertise to that effect. Even if individuals purchase 'healthy' items in bulk, once they are home, overall caloric consumption may be increased due to the bulk purchases. Indeed, we found a positive association between BMI and proximity to supercenters [41]. Future research needs to consider in-store marketing of healthy and regular items and the influence on consumer purchasing behavior.

\section{Conclusion}

The systematic review found that, overall, the micro-level consumer food environment, food items within stores, was not consistently associated with low-income or minority neighborhoods; difference in food prices; dietary outcomes; and BMI. However, given the complex nature of measuring in-store contents and the wide range of food store audit tools used, it remains to be determined if the consumer food environment is a distal determinant of diet and obesity status.

Conflict of interest The authors declare no conflict of interest.

Open Access This article is distributed under the terms of the Creative Commons Attribution Noncommercial License which permits any noncommercial use, distribution, and reproduction in any medium, provided the original author(s) and source are credited.

\section{References}

1. Aggarwal, A., Monsivais, P., Cook, A. J., \& Drewnowski, A. (2011). Does diet cost mediate the relation between socioeconomic position and diet quality? European Journal of Clinical Nutrition, 65, 1059-1066.

2. Andreyeva, T., Blumenthal, D. M., Schwartz, M. B., Long, M. W., \& Brownell, K. D. (2008). Availability and prices of foods across stores and neighborhoods: The case of New Haven, Connecticut. Health Affairs, 27, 1381-1388.

3. Andreyeva, T., Long, M. W., \& Brownell, K. D. (2010). The impact of food prices on consumption: A systematic review of research on the price elasticity of demand for food. American Journal of Public Health, 100, 216-222.

4. Baker, E. A., Schootman, M., Barnidge, E., \& Kelly, C. (2006). The role of race and poverty in access to foods that enable individuals to adhere to dietary guidelines. Preventing Chronic Disease, 3, A76.

5. Ball, K., Jeffery, R. W., Crawford, D. A., Roberts, R. J., Salmon, J., \& Timperio, A. F. (2008). Mismatch between perceived and objective measures of physical activity environments. Preventive Medicine, 47, 294-298.

6. Ball, K., Timperio, A., \& Crawford, D. (2009). Neighbourhood socioeconomic inequalities in food access and affordability. Health \& Place, 15, 578-585.

7. Beaulac, J., Kristjansson, E., \& Cummins, S. (2009). A systematic review of food deserts, 1966-2007. Preventing Chronic Disease, 6, A105.

8. Black, J. L., \& Macinko, J. (2008). Neighborhoods and obesity. Nutrition Reviews, 66, 2-20.

9. Block, D., \& Kouba, J. (2006). A comparison of the availability and affordability of a market basket in two communities in the Chicago area. Public Health Nutrition, 9, 837-845.

10. Block, J. P., Christakis, N. A., O’Malley, A. J., \& Subramanian, S. V. (2011). Proximity to food establishments and body mass index in the Framingham heart study offspring cohort over 30 years. American Journal of Epidemiology, 174(10), 1108-1114.

11. Bodor, J. N., Rice, J. C., Farley, T. A., Swalm, C. M., \& Rose, D. (2010). The association between obesity and urban food environments. Journal of Urban Health: Bulletin of the New York Academy of Medicine, 87, 771-781. 
12. Boone-Heinonen, J., Gordon-Larsen, P., Kiefe, C. I., Shikany, J. M., Lewis, C. E., \& Popkin, B. M. (2011). Fast food restaurants and food stores: Longitudinal associations with diet in young to middle-aged adults: The CARDIA study. Archives of Internal Medicine, 171, 1162-1170.

13. Bustillos, B., Sharkey, J. R., Anding, J., \& Mcintosh, A. (2009). Availability of more healthful food alternatives in traditional, convenience, and nontraditional types of food stores in two rural Texas counties. Journal of the American Dietetic Association, 109, 883-889.

14. Caldwell, E. M., Miller Kobayashi, M., Dubow, W. M., \& Wytinck, S. M. (2009). Perceived access to fruits and vegetables associated with increased consumption. Public Health Nutrition, $12,1743-1750$.

15. Casagrande, S. S., Whitt-Glover, M. C., Lancaster, K. J., OdomsYoung, A. M., \& Gary, T. L. (2009). Built environment and health behaviors among African Americans: A systematic review. American Journal of Preventive Medicine, 36, 174-181.

16. Chung, C., Myers S. L., Jr. (1999). Do the poor pay more for food? An analysis of grocery store availability and food price disparities. Consumer Affairs, 33(2), 276-296.

17. Cole, S. F. S., \& Morland, K. (2010). Analysis of fruit and vegetable cost and quality among racially segregated neighborhoods in Brooklyn, New York. Journal of Hunger \& Environmental Nutrition, 5, 202-215.

18. Courtemanche, C. (2009). Rising cigarette prices and rising obesity: Coincidence or unintended consequence? Journal of Health Economics, 28, 781-798.

19. Creel, J. S., Sharkey, J. R., Mcintosh, A., Anding, J., \& Huber, J. C., Jr. (2008). Availability of healthier options in traditional and nontraditional rural fast-food outlets. BMC Public Health, 8, 395.

20. Cummins, S., \& Macintyre, S. (2009). Are secondary data sources on the neighbourhood food environment accurate? Case-study in Glasgow, UK. Preventive Medicine, 49, 527-528.

21. Cummins, S., Smith, D. M., Aitken, Z., Dawson, J., Marshall, D., Sparks, L., et al. (2010). Neighbourhood deprivation and the price and availability of fruit and vegetables in Scotland. Journal of Human Nutrition and Dietetics: The Official Journal of the British Dietetic Association, 23, 494-501.

22. Dean, W. R., Sharkey, J. R., \& ST John, J. (2011). Pulga (flea market) contributions to the retail food environment of colonias in the South Texas border region. Journal of the American Dietetic Association, 111, 705-710.

23. Donkin, A. J., Dowler, E. A., Stevenson, S. J., \& Turner, S. A. (2000). Mapping access to food in a deprived area: The development of price and availability indices. Public Health Nutrition, 3, 31-38.

24. Drewnowski, A., \& Darmon, N. (2005). Food choices and diet costs: An economic analysis. The Journal of Nutrition, 135, 900-904.

25. Drewnowski, A., \& Eichelsdoerfer, P. (2010). Can low-income Americans afford a healthy diet? Nutrition Today, 44, 246-249.

26. Dunn, R. A., Sharkey, J. R., Lotade-Manje, J., Bouhlal, Y., \& Nayga, R. M., Jr. (2011). Socio-economic status, racial composition and the affordability of fresh fruits and vegetables in neighborhoods of a large rural region in Texas. Nutrition Journal, 10,6 .

27. Edmonds, J., Baranowski, T., Baranowski, J., Cullen, K. W., \& Myres, D. (2001). Ecological and socioeconomic correlates of fruit, juice, and vegetable consumption among African-American boys. Preventive Medicine, 32, 476-481.

28. ERS, U. Available: http://www.ers.usda.gov/Briefing/Rurality/ RuralUrbCon/Index.htm\#anchor. Accessed October 22, 2009.

29. Farley, T. A., Rice, J., Bodor, J. N., Cohen, D. A., Bluthenthal, R. N., \& Rose, D. (2009). Measuring the food environment: Shelf space of fruits, vegetables, and snack foods in stores. Journal of Urban Health, 86, 672-682.
30. Feng, J., Glass, T. A., Curriero, F. C., Stewart, W. F., \& Schwartz, B. S. (2010). The built environment and obesity: A systematic review of the epidemiologic evidence. Health \& Place, 16, 175-190.

31. Fleischhacker, S. E., Evenson, K. R., Rodriguez, D. A., \& Ammerman, A. S. (2011). A systematic review of fast food access studies. Obesity Reviews: an Official Journal of the International Association for the Study of Obesity, 12, e460-e471.

32. Franco, M., Diez-Roux, A. V., Nettleton, J. A., Lazo, M., Brancati, F., Caballero, B., et al. (2009). Availability of healthy foods and dietary patterns: The Multi-Ethnic Study of Atherosclerosis. The American Journal of Clinical Nutrition, 89, 897-904.

33. Franco, M., Diez Roux, A. V., Glass, T. A., Caballero, B., \& Brancati, F. L. (2008). Neighborhood characteristics and availability of healthy foods in Baltimore. American Journal of Preventive Medicine, 35, 561-567.

34. Ghirardelli, A., Quinn, V., \& Sugerman, S. (2011). Reliability of a retail food store survey and development of an accompanying retail scoring system to communicate survey findings and identify vendors for healthful food and marketing initiatives. Journal of Nutrition Education and Behavior, 43, S104-S112.

35. Giskes, K., Kamphuis, C. B., Van Lenthe, F. J., Kremers, S., Droomers, M., \& Brug, J. (2007). A systematic review of associations between environmental factors, energy and fat intakes among adults: Is there evidence for environments that encourage obesogenic dietary intakes? Public Health Nutrition, 10, 1005-1017.

36. Giskes, K., Van Lenthe, F., Avendano-Pabon, M., \& Brug, J. (2011). A systematic review of environmental factors and obesogenic dietary intakes among adults: Are we getting closer to understanding obesogenic environments? Obesity Reviews: An Official Journal of the International Association for the Study of Obesity, 12, e95-e106.

37. Giskes, K., Van Lenthe, F. J., Brug, J., Mackenbach, J. P., \& Turrell, G. (2007). Socioeconomic inequalities in food purchasing: The contribution of respondent-perceived and actual (objectively measured) price and availability of foods. Preventive Medicine, 45, 41-48.

38. Glanz, K., Sallis, J. F., Saelens, B. E., \& Frank, L. D. (2005). Healthy nutrition environments: Concepts and measures. American Journal of Health Promotion, 19, 330-333, ii.

39. Glanz, K., Sallis, J. F., Saelens, B. E., \& Frank, L. D. (2007). Nutrition Environment Measures Survey in stores (NEMS-S): Development and evaluation. American Journal of Preventive Medicine, 32, 282-289.

40. Grigsby-Toussaint, D. S., Zenk, S. N., Odoms-Young, A., Ruggiero, L., \& Moise, I. (2010). Availability of commonly consumed and culturally specific fruits and vegetables in AfricanAmerican and Latino neighborhoods. Journal of the American Dietetic Association, 110, 746-752.

41. Gustafson, A. A., Sharkey, J., Samuel-Hodge, C. D., Jones-Smith, J., Folds, M. C., Cai, J., et al. (2011). Perceived and objective measures of the food store environment and the association with weight and diet among low-income women in North Carolina. Public Health Nutrition, 14, 1032-1038.

42. Guy, C. M., \& David, G. (2004). Measuring physical access to 'healthy foods' in areas of social deprivation: A case study in Cardiff. International Journal of Consumer Studies, 28, 222-234.

43. Harris, J. L., \& Graff, S. K. (2011). Protecting children from harmful food marketing: Options for local government to make a difference. Preventing Chronic Disease, 8, A92.

44. Harrison, M. S., Coyne, T., Lee, A. J., Leonard, D., Lowson, S., Groos, A., et al. (2007). The increasing cost of the basic foods required to promote health in Queensland. The Medical Journal of Australia, 186, 9-14.

45. Hermstad, A. K., Swan, D. W., Kegler, M. C., Barnette, J. K., \& Glanz, K. (2010). Individual and environmental correlates of 
dietary fat intake in rural communities: A structural equation model analysis. Social Science and Medicine, 71, 93-101.

46. Horowitz, C. R., Colson, K. A., Hebert, P. L., \& Lancaster, K. (2004). Barriers to buying healthy foods for people with diabetes: Evidence of environmental disparities. American Journal of Public Health, 94, 1549-1554.

47. Hosler, A. S. (2009). Retail food availability, obesity, and cigarette smoking in rural communities. The Journal of Rural Health: Official Journal of the American Rural Health Association and the National Rural Health Care Association, 25, 203-210.

48. Hosler, A. S., Rajulu, D. T., Fredrick, B. L., \& Ronsani, A. E. (2008). Assessing retail fruit and vegetable availability in urban and rural underserved communities. Preventing Chronic Disease, 5, A123.

49. Jetter, K. M., \& Cassady, D. L. (2006). The availability and cost of healthier food alternatives. American Journal of Preventive Medicine, 30, 38-44.

50. Jilcott, S. B., Wade, S., Mcguirt, J. T., Wu, Q., Lazorick, S., \& Moore, J. B. (2011). The association between the food environment and weight status among eastern North Carolina youth. Public Health Nutrition, 14, 1610-1617.

51. Kipke, M. D., Iverson, E., Moore, D., Booker, C., Ruelas, V., Peters, A. L., et al. (2007). Food and park environments: Neighborhood-level risks for childhood obesity in East Los Angeles. The Journal of Adolescent Health: Official Publication of the Society for Adolescent Medicine, 40, 325-333.

52. Krukowski, R. A., \& West, D. S. (2010). Consideration of the food environment in cancer risk reduction. Journal of the American Dietetic Association, 110, 842-844.

53. Latham, J., \& Moffat, T. (2007). Determinants of variation in food cost and availability in two socioeconomically contrasting neighbourhoods of Hamilton, Ontario, Canada. Health \& Place, 13, 273-287.

54. Lee, R. E., Heinrich, K. M., Medina, A. V., Regan, G. R., ReeseSmith, J. Y., Jokura, Y., et al. (2010). A picture of the healthful food environment in two diverse urban cities. Environmental Health Insights, 4, 49-60.

55. Leibtag, E. (2005). Where you shop matters: Store formats drive variation in retailfood prices. Amber Waves, Nov 2005. http://www. ers.usda.gov/AmberWaves/November05/Features/WhereYouShop. htm. Accessed 8 October 2008.

56. Leone, A. F., Rigby, S., Betterley, C., Park, S., Kurtz, H., Johnson, M. A., et al. (2011). Store type and demographic influence on the availability and price of healthful foods, Leon County, Florida, 2008. Preventing Chronic Disease, 8, A140.

57. Liese, A. D., Weis, K. E., Pluto, D., Smith, E., \& Lawson, A. (2007). Food store types, availability, and cost of foods in a rural environment. Journal of the American Dietetic Association, 107, 1916-1923.

58. Lovasi, G. S., Moudon, A. V., Smith, N. L., Lumley, T., Larson, E. B., Sohn, D. W., et al. (2008). Evaluating options for measurement of neighborhood socioeconomic context: Evidence from a myocardial infarction case-control study. Health Place, 14, 453-467.

59. Lucan, S. C., Barg, F. K., \& Long, J. A. (2010). Promoters and barriers to fruit, vegetable, and fast-food consumption among urban, low-income African Americans-a qualitative approach. American Journal of Public Health, 100, 631-635.

60. Ludwig, J., Sanbonmatsu, L., Gennetian, L., Adam, E., Duncan, G. J., Katz, L. F., et al. (2011). Neighborhoods, obesity, and diabetes-a randomized social experiment. The New England Journal of Medicine, 365, 1509-1519.

61. Mccullough, M. L., \& Willett, W. C. (2006). Evaluating adherence to recommended diets in adults: The Alternate Healthy Eating Index. Public Health Nutrition, 9, 152-157.

62. Mckinnon, R. A., Reedy, J., Morrissette, M. A., Lytle, L. A., \& Yaroch, A. L. (2009). Measures of the food environment: A compilation of the literature, 1990-2007. American Journal of Preventive Medicine, 36, S124-S133.

63. Mhurchu, C. N. (2010). Food costs and healthful diets: The need for solution-oriented research and policies. The American Journal of Clinical Nutrition, 92, 1007-1008.

64. Morland, K., \& Filomena, S. (2007). Disparities in the availability of fruits and vegetables between racially segregated urban neighbourhoods. Public Health Nutrition, 10, 1481-1489.

65. O'Connell, M., Buchwald, D. S., \& Duncan, G. E. (2011). Food access and cost in American Indian communities in Washington State. Journal of the American Dietetic Association, 111, 1375-1379.

66. Pearce, J., Hiscock, R., Blakely, T., \& Witten, K. (2008). The contextual effects of neighbourhood access to supermarkets and convenience stores on individual fruit and vegetable consumption. Journal of Epidemiology and Community Health, 62, 198-201.

67. Pearson, T., Russell, J., Campbell, M. J., \& Barker, M. E. (2005). Do 'food deserts' influence fruit and vegetable consumption?-A cross-sectional study. Appetite, 45, 195-197.

68. Rose, D. (2010). Access to healthy food: A key focus for research on domestic food insecurity. The Journal of Nutrition, 140, 1167-1169.

69. Rose, D., Bodor, J. N., Hutchinson, P. L., \& Swalm, C. M. (2010). The importance of a multi-dimensional approach for studying the links between food access and consumption. The Journal of Nutrition, 140, 1170-1174.

70. Rose, D., Hutchinson, P. L., Bodor, J. N., Swalm, C. M., Farley, T. A., Cohen, D. A., et al. (2009). Neighborhood food environments and Body Mass Index: The importance of in-store contents. American Journal of Preventive Medicine, 37, 214-219.

71. Schulz, A. J., Zenk, S. N., Israel, B. A., Mentz, G., Stokes, C., \& Galea, S. (2008). Do neighborhood economic characteristics, racial composition, and residential stability predict perceptions of stress associated with the physical and social environment? Findings from a multilevel analysis in Detroit. Journal of Urban Health, 85, 642-661.

72. Sharkey, J. R. (2009). Measuring potential access to food stores and food-service places in rural areas in the U.S. American Journal of Preventive Medicine, 36, S151-S155.

73. Sharkey, J. R., Johnson, C. M., \& Dean, W. R. (2010). Food access and perceptions of the community and household food environment as correlates of fruit and vegetable intake among rural seniors. BMC Geriatrics, 10, 32.

74. Sharkey, J. R., Johnson, C. M., Dean, W. R., \& Horel, S. A. (2011). Association between proximity to and coverage of traditional fast-food restaurants and non-traditional fast-food outlets and fast-food consumption among rural adults. International Journal of Health Geographics, 10, 37.

75. Sharkey, J. R., Johnson, C. M., Dean, W. R., \& Horel, S. A. (2011). Focusing on fast food restaurants alone underestimates the relationship between neighborhood deprivation and exposure to fast food in a large rural area. Nutrition Journal, 10, 10.

76. Sloane, D. C., Diamant, A. L., Lewis, L. B., Yancey, A. K., Flynn, G., Nascimento, L. M., et al. (2003). Improving the nutritional resource environment for healthy living through community-based participatory research. Journal of General Internal Medicine, 18, 568-575.

77. Smith, D. M., Cummins, S., Taylor, M., Dawson, J., Marshall, D., Sparks, L., et al. (2010). Neighbourhood food environment and area deprivation: Spatial accessibility to grocery stores selling fresh fruit and vegetables in urban and rural settings. International Journal of Epidemiology, 39, 277-284.

78. Spence, J. C., Cutumisu, N., Edwards, J., Raine, K. D., \& Smoyer-Tomic, K. (2009). Relation between local food environments and obesity among adults. BMC Public Health, 9, 192.

79. Story, M., Kaphingst, K. M., Robinson-O'Brien, R., \& Glanz, K. (2008). Creating healthy food and eating environments: Policy 
and environmental approaches. Annual Review of Public Health, 29, 253-272.

80. Sturm, R., \& Datar, A. (2008). Food prices and weight gain during elementary school: 5-year update. Public Health, 122, $1140-1143$.

81. Thornton, L. E., Crawford, D. A., \& Ball, K. (2010). Neighbourhood-socioeconomic variation in women's diet: The role of nutrition environments. European Journal of Clinical Nutrition, 64, 1423-1432.

82. Willett, W. C., \& Ludwig, D. S. (2011). The 2010 dietary guidelines-the best recipe for health? The New England Journal of Medicine, 365, 1563-1565.

83. Williams, P. L., Johnson, C. P., Kratzmann, M. L., Johnson, C. S., Anderson, B. J., \& Chenhall, C. (2006). Can households earning minimum wage in Nova Scotia afford a nutritious diet? Canadian Journal of Public Health. Revue canadienne de sante publique, 97, 430-434.

84. Winkler, E., Turrell, G., \& Patterson, C. (2006). Does living in a disadvantaged area mean fewer opportunities to purchase fresh fruit and vegetables in the area? Findings from the Brisbane food study. Health \& Place, 12, 306-319.

85. Yeh, M. C., Ickes, S. B., Lowenstein, L. M., Shuval, K., Ammerman, A. S., Farris, R., et al. (2008). Understanding barriers and facilitators of fruit and vegetable consumption among a diverse multi-ethnic population in the USA. Health Promotion International, 23, 42-51.

86. Zenk, S. N., Schulz, A. J., Israel, B. A., James, S. A., Bao, S., \& Wilson, M. L. (2006). Fruit and vegetable access differs by community racial composition and socioeconomic position in Detroit, Michigan. Ethnicity and Disease, 16, 275-280.

87. Zenk, S. N., Wilbur, J., Wang, E., Mcdevitt, J., Oh, A., Block, R., et al. (2009). Neighborhood environment and adherence to a walking intervention in African American women. Health Education \& Behavior, 36, 167-181.

88. Cummins, S., \& McIntyre, S. (2002). "Food Deserts"—evidence and assumption in health policy making. BMJ, 325, 436-438. 